\title{
Insufficient modification of atherosclerosis risk factors in PAD patients
}

\author{
Katarzyna Skórkowska-Telichowska ${ }^{1-3, B-D}$, Katarzyna Kropielnicka ${ }^{1,4, B, C}$, Katarzyna Bulińska, ${ }^{1,4, B, C}$, \\ Urszula Pilch ${ }^{1,4, B, C}$, Marek Woźniewski ${ }^{4, A, F}$, Andrzej Szuba ${ }^{1-3, A, D-F}$, Ryszard Jasińnski' ${ }^{4, B, F}$ \\ ${ }^{1}$ WroVasc-Integrated Medical Cardiovascular Center, Regional Specialist Hospital, Research and Development Center, Wrocław, Poland \\ 2 Department of Internal Medicine, $4^{\text {th }}$ Military Hospital, Wrocław, Poland \\ ${ }^{3}$ Division of Angiology, Faculty of Health Sciences, Wroclaw Medical University, Poland \\ ${ }^{4}$ Department of Rehabilitation, University School of Physical Education, Wrocław, Poland \\ A - research concept and design; $\mathrm{B}$ - collection and/or assembly of data; $\mathrm{C}$ - data analysis and interpretation; \\ $D$ - writing the article; $E$ - critical revision of the article; $F$ - final approval of the article
}

Address for correspondence

Katarzyna Skórkowska-Telichowska

E-mail: cathcor@poczta.onet.pl

\section{Funding sources}

This publication is a part of the "WroVasc

- Integrated Cardiovascular Centre" project, cofinanced by the European Regional Development Fund, within the Innovative Economy Operational Program, 2007-2013, conducted in the Regional Specialist Hospital, Research and Development Center in Wrocław, Poland.

Conflict of interest None declared

Received on February 9, 2016 Reviewed on August 11, 2016 Accepted on February 14, 2017

\begin{abstract}
Background. An aggressive reduction of cardiovascular risk factors in patients with intermittent claudication (IC) is extremely important.

Objectives. The aim of this study was to investigate patients' adherence to current guidelines for the recognition and reduction of atherosclerosis risk factors in peripheral arterial disease (PAD) in Poland.

Material and methods. The study included 126 patients with PAD stage II, according to the Fontaine Classification, who over a period of 2 years attended an angiological outpatient clinic and were referred for physical rehabilitation.

Results. In the 77\% of PAD patients diagnosed with dyslipidemia, 72\% had hypertension and 31\% had diabetes. Suboptimal treatment was being given to $85.5 \%$ of patients with dyslipidemia, to $26 \%$ of patients with hypertension and to $95 \%$ of diabetics. In this study, a diagnosis of dyslipidemia, hypertension and diabetes was made for the $1^{\text {st }}$ time in $22 \%, 7 \%$ and $4 \%$ of patients, respectively. As many as $17.5 \%$ of PAD patients with claudication were not receiving any antiplatelet therapy.

Conclusions. The diagnosis of dyslipidemia was insufficient (about $1 / 3$ of the patients were undiagnosed), and diagnoses of hypertension and diabetes prevailed. It was established that the effective control of risk factors using relevant treatment is insufficient in dyslipidemia, hypertension and diabetes. Antiplatelet therapy was not prescribed in approx. $20 \%$ of cases.
\end{abstract}

Key words: diabetes, smoking, arterial hypertension, antiplatelet therapy, dyslipidemia

DOI

10.17219/acem/68983

Copyright

Copyright by Author(s)

This is an article distributed under the terms of the

Creative Commons Attribution Non-Commercial License

(http://creativecommons.org/licenses/by-nc-nd/4.0/) 


\section{Introduction}

The guidelines on the Diagnosis and Treatment of Peripheral Artery Disease, established by the European Society of Cardiology (ESC) and applicable in Poland, determine and facilitate the treatment of atherosclerosis that occurs in different vascular beds. ${ }^{1}$ The guidelines should help angiologists make proper decisions in their daily practice. However, due to a lack of cohort studies, the very general nature of the recommendations and the conservative character of the guidelines, the final decisions concerning individual patients must be made by the responsible physician. In peripheral artery disease (PAD) patients, a multidisciplinary approach is recommended in order to establish a management strategy (class of recommendation: I, level of evidence: C). The most effective strategy for PAD treatment, according to the ESC guidelines, is the aggressive reduction of atherosclerosis risk factors, which include atherogenic dyslipidemia, hypertension, diabetes, obesity, and smoking.

Apart from lifestyle modifications, such as regular exercise, a Mediterranean diet and cessation of smoking, patient care should include pharmacological treatment to control blood pressure (treatment with angiotensin-converting enzyme [ACE] inhibitors and beta-blockers have shown beneficial effects), an appropriate lipid-lowering statin therapy, and glycaemia treatment in diabetic patients. ${ }^{1}$ All PAD patients should receive antiplatelet therapy. ${ }^{1}$

The aim of this study was to determine the adherence to the current recommendations regarding the reduction of atherosclerosis risk factors in patients with PAD in Poland.

\section{Material and methods}

From a group of 219 subjects with atherosclerosis of the lower extremities who were examined in the angiology outpatient unit over a 2-year period (2011-2013), 126 subjects fulfilled the criteria for participation in physical exercise training and were enrolled in the study.

Recruitment into the rehabilitation program was limited to patients with stable claudication without any limitations or contraindications for physical exercise. The inclusion and exclusion criteria for participation in physical training are listed in Table 1.

\section{Risk factor profile}

The profile of risk factors and treatment were determined during admission to the angiology outpatient unit based on a self-reported medical history. Measurement of blood pressure and laboratory tests were also performed during the visit.

In the study, references to current treatment guidelines for dyslipidemia, hypertension and diabetes reflected the
Table 1. Inclusion and exclusion criteria for participation in the study ${ }^{2}$

Inclusion criteria
- Age over 40 years
- Documented IC which is stable for at least 3 months, considered for
physical rehabilitation program
- IC distance: $30-320$ m (stage II according to the Fontaine
Classification), ABI $\leq 0.9$
- Exclusion criteria
- PAD Fontaine stage I (pain-free distance on a treadmill $>500$ m,
- Physical limitation due to advanced cardiovascular disease,
- Vrthopedic disorders, balance disorders, or dementia
- Logistical obstacles: distance to the place of physical rehabilitation
- Simultaneous participation in another research programs
- Anticipated problems with patients' compliance with the program
ABI - ankle brachial index; IC - intermittent claudication; PAD - peripheral
artery disease.

ESC Guidelines on the Diagnosis and Treatment of Peripheral Arterial Disease, 2011. ${ }^{1}$

Dyslipidemia was defined in accordance with the Third Report of the Adult Treatment Panel (ATP III) of the National Cholesterol Education Program guidelines as a high concentration of total cholesterol, low-density lipoprotein (LDL) cholesterol $\geq 100 \mathrm{mg} / \mathrm{dL}$, triglycerides $\geq 150 \mathrm{mg} / \mathrm{dL}$, and/or a low high-density lipoprotein (HDL) cholesterol level of $<40 \mathrm{mg} / \mathrm{dL}$ for men and $<50 \mathrm{mg} / \mathrm{dL}$ for women. ${ }^{3}$

Optimal treatment of previously recognized dyslipidemia was defined as an LDL cholesterol level of $\leq 100 \mathrm{mg} / \mathrm{dL}$ (in asymptomatic PAD patients), or ideally, a level of $\leq 70 \mathrm{mg} / \mathrm{dL}$ (in symptomatic patients - that is, with intermittent claudication [IC]), and all cholesterol and triglyceride counts within normal ranges.

Arterial hypertension was outlined by the $8^{\text {th }}$ Joint National Committee guidelines and defined as an systolic blood pressure/diastolic blood pressure (SBP/DBP) of $\geq 140 / 90 \mathrm{~mm} \mathrm{Hg}$ in patients aged $<60$ years and $\geq 150 / 90$ $\mathrm{mm} \mathrm{Hg}$ in patients aged $\geq 60$ years, with or without antihypertensive treatment. ${ }^{4}$

Optimal treatment in patients with previously diagnosed arterial hypertension was defined as an SBP/ DBP of $\leq 140 / 90 \mathrm{~mm} \mathrm{Hg}$ in patients aged $\leq 60$ years and of $\leq 150 / 90 \mathrm{~mm} \mathrm{Hg}$ in patients aged $\geq 60$ years.

A glycated hemoglobin $\left(\mathrm{HbA}_{1 \mathrm{c}}\right)$ level of $\geq 7 \%$ indicated suboptimal glycemic control in diabetics. Newly diagnosed diabetes was defined as a fasting glucose concentration of $\geq 126 \mathrm{mg} / \mathrm{dL}$ accompanied by symptoms of uncontrolled diabetes. Impaired fasting glucose (defined as prediabetes) was established as a fasting glucose level between $110 \mathrm{mg} / \mathrm{dL}$ and $125 \mathrm{mg} / \mathrm{dL} .{ }^{5}$

Routine laboratory tests were performed on peripheral blood collected in the morning after an 8-h fast. Laboratory tests included a complete blood count with a differential and biochemical profile, including blood urea, creatinine, $C$ reactive protein (CRP), fibrinogen, a lipid panel with total cholesterol, HDL cholesterol, LDL cholesterol, and triglycerides, as well as sodium, potassium and glucose levels. 
Table 2. Entire population data (patients' characteristics and disease history). Descriptive data is presented as mean \pm standard deviation or number (\%)

\begin{tabular}{|c|c|}
\hline \multicolumn{2}{|c|}{ General information } \\
\hline Number of subjects & 126 \\
\hline Age [years] & $67.4 \pm 8.3$ \\
\hline \multicolumn{2}{|c|}{ Gender } \\
\hline Female, n (\%) & $34(27)$ \\
\hline Male, n (\%) & $92(73)$ \\
\hline BMI $\left[\mathrm{kg} / \mathrm{m}^{2}\right]$ & $27.5 \pm 4$ \\
\hline City dwellers, n (\%) & $120(95.3)$ \\
\hline Village dwellers, n (\%) & $6(4.7)$ \\
\hline \multicolumn{2}{|c|}{ Angiological profile } \\
\hline \multicolumn{2}{|c|}{ Type of ischemia, n (\%) } \\
\hline Aorto-iliac & $9(7)$ \\
\hline Femoro-popliteal & $74(59)$ \\
\hline Infra-popliteal & $24(19)$ \\
\hline Multilevel lesions & $19(15)$ \\
\hline \multicolumn{2}{|c|}{ Fontaine class, n (\%) } \\
\hline Class II a (>200 m) & $8(6.4)$ \\
\hline Class II b (<200 m) & $118(93.6)$ \\
\hline$A B \mid$ & $0.61 \pm 0.22$ \\
\hline Initial claudication distance [m] & $95.9 \pm 58$ \\
\hline Absolute claudication distance [m] & $175.6 \pm 98.8$ \\
\hline \multicolumn{2}{|c|}{ Medical history, n (\%) } \\
\hline Diagnosed diabetes type 2 & $39(31)$ \\
\hline Diagnosed arterial hypertension & $91(72)$ \\
\hline Diagnosed dyslipidemia & $97(77)$ \\
\hline Diagnosed CHD & $\begin{array}{c}54 \text { (42.8), after ACS } 20 \text { (15.8); } \\
\text { stabile angina pectoris } 34 \text { (27) }\end{array}$ \\
\hline History of CHF & $41(32.5)$ \\
\hline History of stroke & $13(10.3)$ \\
\hline History of cancer & $15(11.9)$ \\
\hline History of thyroid diseases & $10(7.94)$ \\
\hline History of kidney failure & $15(11.9)$ \\
\hline Chronic venous insufficiency & $11(8.7)$ \\
\hline Osteoarthritis & $37(29.3)$ \\
\hline COPD & $2(1.6)$ \\
\hline Osteoporosis & $2(1.6)$ \\
\hline
\end{tabular}

$\mathrm{ABI}$ - ankle brachial index; ACS - acute coronary syndrome; BMI - body mass index; CHD - coronary heart disease; CHF - chronic heart failure; COPD - chronic obstructive pulmonary disease.

This was performed using standard laboratory techniques carried out in the angiology unit (Table 2).

The patients' profile of atherosclerosis risk factors allowed for the division of the subjects into 3 groups:

1. Patients with previously diagnosed risk factors, treated optimally according to applicable standards;

2. Patients with previously diagnosed risk factors whose treatment was not optimal (the therapeutic objectives were not achieved);

3. Patients in whom atherosclerosis risk factors had not previously been diagnosed.

\section{Statistical analysis}

Normality was tested using the D'Agostino-Pearson test. Comparison between quantitative variables was performed using the Mann-Whitney U test (for 2 variables) and the Kruskall-Wallis test (for more than 2 variables). Analysis of the relationships between qualitative variables was performed using the $\chi^{2}$ test. Statistical analysis was performed using $\mathrm{R}$ for Windows (v. 3.1.2). All results with $\mathrm{p}<0.05$ were considered significant. The demographic and clinical characteristics of the study group were reported as median and interquartile ranges or as counts and percentages, as appropriate.

\section{Ethical approval}

Ethical approval was obtained from the local bioethics committee (Bioethics Committee, Wroclaw Medical University, Poland, No. 130/2008 KB). All the patients were provided with written information on the purpose and design of the study.

\section{Results}

The main clinical and biochemical data of the examined group are summarized in Table 3.

\section{Dyslipidemia}

A history of dyslipidemia was reported in 97 subjects (77\%), with a mean level of total cholesterol amounting to $167 \pm 36 \mathrm{mg} / \mathrm{dL}$, mean LDL cholesterol of $92 \pm 30 \mathrm{mg} / \mathrm{dL}$, mean HDL cholesterol of $46.5 \pm 11 \mathrm{mg} / \mathrm{dL}$, and a mean level of triglycerides of $141 \pm 80 \mathrm{mg} / \mathrm{dL}$.

Optimal therapy was observed in 14 subjects $(14.4 \%$ of the 97 patients) with a mean level of total cholesterol amounting to $122 \pm 17 \mathrm{mg} / \mathrm{dL}$, mean LDL cholesterol of $53 \pm 9 \mathrm{mg} / \mathrm{dL}$, mean HDL cholesterol level of $49 \pm 11 \mathrm{mg} / \mathrm{dL}$, and triglycerides of $97 \pm 34 \mathrm{mg} / \mathrm{dL}$.

Suboptimal therapy was observed in 83 subjects $(85.5 \%$ of the 97 patients) with a mean level of total cholesterol amounting to $174 \pm 33 \mathrm{mg} / \mathrm{dL}$, mean LDL cholesterol of $98 \pm 27 \mathrm{mg} / \mathrm{dL}$, mean HDL cholesterol of $46 \pm 11 \mathrm{mg} / \mathrm{dL}$, and triglycerides of $148 \pm 83 \mathrm{mg} / \mathrm{dL}$. Undiagnosed cases of dyslipidemia were found in 28 subjects ( $22 \%$ of the total sample of 126 patients). These were new cases of dyslipidemia with mean levels of total cholesterol amounting to $202 \pm 42 \mathrm{mg} / \mathrm{dL}$, mean LDL cholesterol of $123 \pm 32 \mathrm{mg} / \mathrm{dL}$, mean HDL cholesterol of $45 \pm 8 \mathrm{mg} / \mathrm{dL}$, and triglycerides of $154 \pm 84 \mathrm{mg} / \mathrm{dL}$. Patients that had not been diagnosed before participating in the study had significantly higher total cholesterol levels than the group undergoing treatment $(\mathrm{p}=0.0003)$ and significantly higher LDL cholesterol levels ( $p=0.0001)$. HDL cholesterol levels and triglycerides were higher in the untreated group, but not significantly. 
Table 3. Risk factor profile of PAD patients $(n=126)$. Descriptive data is presented as mean \pm standard deviation or number $(\%)$

\begin{tabular}{|c|c|c|c|c|}
\hline Variable & $\begin{array}{l}\text { Entire population } \\
\qquad(n=126)\end{array}$ & $\begin{array}{l}\text { A: patients with } \\
\text { diagnosed diabetes } \\
(n=39 ; 30.952 \%)\end{array}$ & $\begin{array}{c}\text { B: patients without } \\
\text { diabetes } \\
(n=87 ; 69.047 \%)\end{array}$ & $\begin{array}{l}p \text {-value } \\
\text { (A vs B) }\end{array}$ \\
\hline Fasting glucose level [mg/dL] & $117 \pm 35$ & $147 \pm 35$ & $103 \pm 24$ & 0.0001 \\
\hline $\mathrm{HbA}_{1 c}[\%]$ & $10 \pm 0.5$ & $10 \pm 0.5$ & - & - \\
\hline Total cholesterol [mg/dL] & $174 \pm 41$ & $169 \pm 39$ & $177 \pm 41$ & 0.26 \\
\hline LDL cholesterol [mg/dL] & $98 \pm 33$ & $93 \pm 30$ & $101 \pm 34$ & 0.12 \\
\hline HDL cholesterol [mg/dL] & $46 \pm 10$ & $44 \pm 10$ & $47 \pm 10$ & 0.16 \\
\hline Triglycerides [mg/dL] & $144 \pm 81$ & $149.5 \pm 73$ & $141 \pm 85$ & 0.19 \\
\hline CRP $[\mathrm{mg} / \mathrm{L}]$ & $6 \pm 13$ & $6.5 \pm 20$ & $6 \pm 9$ & 0.022 \\
\hline Homocysteine [umol/L] & $14 \pm 5$ & $13 \pm 5$ & $15 \pm 5$ & 0.16 \\
\hline Fibrynogen [g/L] & $4 \pm 1$ & $4 \pm 1$ & $4 \pm 1$ & 0.46 \\
\hline $\begin{array}{l}\text { SBP [mm Hg] } \\
\text { DBP [mm Hg] }\end{array}$ & $\begin{array}{c}133 \pm 15 \\
78 \pm 7\end{array}$ & $\begin{array}{c}133 \pm 15 \\
77 \pm 8\end{array}$ & $\begin{array}{c}133 \pm 15 \\
78 \pm 7\end{array}$ & 0.62 \\
\hline Pulse rate [bpm] & $75 \pm 12$ & $74 \pm 12$ & $76 \pm 13$ & 0.85 \\
\hline$A B \mid$ & $0.6 \pm 0.2$ & $0.64 \pm 0.3$ & $0.60 \pm 0.1$ & 0.92 \\
\hline BMI $\left[\mathrm{kg} / \mathrm{m}^{2}\right]$ & $27.5 \pm 4$ & $28.7 \pm 3$ & $27.0 \pm 4$ & 0.018 \\
\hline Current smokers, n (\%) & $32(25 \%)$ & $10(8 \%)$ & $22(17.5 \%)$ & 0.43 \\
\hline Ever-smokers, n (\%) & $17(13.5 \%)$ & $3(2.3 \%)$ & $14(11 \%)$ & 0.43 \\
\hline Initial claudication distance [m] & $95.9 \pm 58$ & $106 \pm 72$ & $91 \pm 50$ & 0.94 \\
\hline Absolute claudication distance [m] & $175 \pm 99$ & $179 \pm 107$ & $174 \pm 95$ & 0.76 \\
\hline
\end{tabular}

p-value of < 0.05 was considered statistically significant; BMI - body mass index; CRP - C reactive protein; LDL - low-density lipoprotein; HDL - high-density lipoprotein; SBP - systolic blood pressure; DBP - diastolic blood pressure; ABI - ankle brachial index.

An absence of dyslipidemia was observed in only 1 case, with a total cholesterol amounting to $116 \mathrm{mg} / \mathrm{dL}$, LDL cholesterol level of $70 \mathrm{mg} / \mathrm{dL}$, HDL cholesterol of $33 \mathrm{mg} / \mathrm{dL}$, and triglyceride level of $65 \mathrm{mg} / \mathrm{dL}$.

In subjects with previously diagnosed dyslipidemia, the most commonly prescribed medications were statins (88 subjects $-91 \%$ ), while 5 subjects $(5 \%)$ were taking 2 cholesterollowering agents (statin + fibrate) and 4 subjects (4\%) were on fibrate therapy. Two main types of statins were being administered: $76 \%$ of patients $(n=67)$ received atorvastatin and $20 \%(n=17)$ were given simvastatin. The patients considered to be receiving optimal treatment had significantly lower total cholesterol levels ( $\mathrm{p}=0.0001)$, LDL cholesterol levels $(\mathrm{p}=0.0001)$ and triglycerides $(\mathrm{p}=0.022)$. HDL cholesterol levels did not vary significantly, but were higher in the group treated optimally.

\section{Hypertension}

Arterial hypertension was diagnosed in 91 subjects prior to the study, representing $72 \%$ of the study sample; in this group of patients, the mean SBP was $134 \pm 16 \mathrm{~mm} \mathrm{Hg}$ and DBP was $77 \pm 8 \mathrm{~mm} \mathrm{Hg}$.

Management of hypertension was suboptimal in 24 subjects (26\% of subjects with hypertension). In this group, the mean SBP was $156 \pm 9 \mathrm{~mm} \mathrm{Hg}$ and DBP was $80 \pm 7 \mathrm{~mm} \mathrm{Hg}$.

The optimal treatment was prescribed in 67 patients (74\% of subjects with hypertension) with a mean SBP amounting to $127 \pm 10 \mathrm{~mm} \mathrm{Hg}$ and DBP of $76 \pm 8 \mathrm{~mm} \mathrm{Hg}$.
Hypertension was unrecognized in $7 \%(\mathrm{n}=9)$ of the sample with a mean SBP of $150 \pm 8 \mathrm{~mm} \mathrm{Hg}$ and DBP of $88 \pm 5 \mathrm{~mm} \mathrm{Hg}$. All 3 groups of patients (those treated optimally, treated suboptimally and undiagnosed) differed significantly in terms of both SBP $(\mathrm{p}=0.0005)$ and DBP $(\mathrm{p}=0.0001)$. An absence of hypertension was observed in 26 patients (20.63\%).

In patients with previously diagnosed hypertension, $20 \%$ ( $n=18)$ were receiving monotherapy, while $21 \%(n=19)$ were receiving dual hypertensive therapy. Triple therapy had been prescribed in $30 \%$ of subjects $(n=27)$, representing the most common regimen. A combination of 4 medicines was prescribed to $21 \%$ of patients $(n=19)$. Five medicines had been prescribed less frequently $(6 \% ; n=6)$, though 2 patients (2\%) were taking 6 medicines. There were no significant differences in SBP or DBP relative to the number of antihypertensive medications used; nevertheless, the lowest pressure was observed in patients treated with 3 medications.

The most frequently used medications were ACE inhibitors (57\% of subjects with diagnosed hypertension, $\mathrm{n}=52$ ) and diuretics (54\% of subjects with diagnosed hypertension, $\mathrm{n}=49$ ), followed by calcium channel blockers and other kinds of antihypertensive medications. Of the ACE inhibitors, the most frequently prescribed medications were ramipril $(54 \%, \mathrm{n}=28)$, followed by perindopril (23\%, $\mathrm{n}=12)$, quinapril $(15 \%, \mathrm{n}=8)$ and other medications. The most frequently prescribed diuretics were Indapen ${ }^{\circledR}$ SR (45\% of patients who received diuretics, 
$\mathrm{n}=22$ ), hydrochlorothiazide (26.5\% of patients who received diuretics, $\mathrm{n}=13$ ), and loop diuretics, such as furosemide and torasemide (28.6\% of patients who received diuretics, $\mathrm{n}=14)$.

Fifty-five patients ( $43.6 \%$ of the entire study population) were using beta-blockers, bisoprolol being the most frequently prescribed medication $(54.5 \%, \mathrm{n}=30)$, followed by carvedilol $(18 \%, \mathrm{n}=10)$, metoprolol $(12.7 \%, \mathrm{n}=7)$ and nebivolol $(9 \%, \mathrm{n}=5)$.

The most frequently administered drug combination, which was given to 14 patients (15\%), consisted of perindopril and Indapen ${ }^{\circledR}$ SR.

\section{Diabetes}

A history of diabetes was reported in 39 patients (31\%). The mean fasting blood glucose level was $147 \pm 36 \mathrm{mg} / \mathrm{dL}$, and the mean $\mathrm{HbA}_{1 \mathrm{c}}$ level was $10 \pm 0.5 \%$.

Suboptimal glycemic control was found in 37 cases (95\%), in which the mean fasting blood glucose level was $152 \pm 4 \mathrm{mg} / \mathrm{dL}$. In 2 patients (5\%) who exhibited optimal glucose control, the mean fasting blood glucose was $85.5 \pm 0.7 \mathrm{mg} / \mathrm{dL}$.

During the study, prediabetes (impaired fasting glucose) was diagnosed for the $1^{\text {st }}$ time in 14 subjects $(11 \%)$; the mean fasting glucose level in this group was $116 \pm 5 \mathrm{mg} / \mathrm{dL}$. Newly diagnosed cases of diabetes affected 5 patients (4\%). The mean fasting glucose level in this group was $181 \pm 40 \mathrm{mg} / \mathrm{dL}$.

Normal glucose control was found in 68 patients (54\%) with fasting blood glucose levels of $91 \pm 7 \mathrm{mg} / \mathrm{dL}$. All 3 groups of patients (those with diagnosed diabetes, those with existing but previously undiagnosed diabetes, and healthy individuals without diabetes) differed significantly in terms of fasting glucose levels $(\mathrm{p}=0.0001)$.

Out of the 39 subjects who had diabetes, 29 were taking oral hypoglycemic medications, 3 subjects were being treated with insulin therapy and 7 subjects received both insulin and oral hypoglycemic therapy. In the group of patients who were administered oral medicines, 16 received monotherapy (a mean fasting glucose level of $125 \pm 37 \mathrm{mg} / \mathrm{dL}$ ), 11 patients received double therapy (a mean fasting glucose level of $152 \pm 21 \mathrm{mg} / \mathrm{dL}$ ) and 2 patients were administered triple therapy (with a mean fasting glucose level of $152.5 \pm 37 \mathrm{mg} / \mathrm{dL}$ ). The most frequently prescribed oral hypoglycemic medicine was metformin. Patients who were treated with insulin had a mean fasting glucose level of $144.6 \pm 5 \mathrm{mg} / \mathrm{dL}$.

Diabetes, hypertension and dyslipidemia were observed in 28 subjects concomitantly $(22.2 \%$ of the entire study population). Diabetes plus hypertension was observed in 6 subjects ( $5 \%$ of the entire study population). Diabetes plus dyslipidemia (without hypertension) was observed in 2 cases (1.6\%). Only 3 subjects who were diagnosed with diabetes did not have either hypertension or dyslipidemia.

\section{Anticoagulation/antiplatelet therapy}

Antiplatelet therapy was being used by 104 subjects (82.5\% of the 126 patients), the most common being monotherapy. Aspirin monotherapy was being taken by 74 subjects $(59 \%)$, followed by clopidogrel $(1.6 \%, \mathrm{n}=2)$ and ticlopidine $(1.6 \%, \mathrm{n}=2)$. Dual therapy was administered to 19 patients (15\%). The most common therapies were the concomitant treatment of aspirin with clopidogrel (17 patients, $13.5 \%$ ) and aspirin with ticlopidine (2 patients, $1.6 \%)$. The prescription of dual therapy was not the result of previous invasive interventional cardiology, but was due to atherosclerosis of the lower limbs. One subject (0.8\%) was administered triple therapy: aspirin, clopidogrel and acenokumarol. Anticoagulation therapy was being given to 3 patients only (4\%). Twenty-two individuals $(17.5 \%)$ were not currently receiving anticoagulant or antiplatelet therapy.

\section{Other medicines taken for peripheral artery disease}

Thirty-five subjects from the entire study population (28\%) were taking pentoxifylline, the average dose being $1200 \mathrm{mg}$ per day (600-1800 mg). Sulodexide was taken by 13 patients (10.3\%) with an average dose of $500 \mathrm{mg}$ per day. Bencyclane was taken by 15 patients (12\%); the average dose was $400 \mathrm{mg}$ per day.

\section{Smokers}

In the entire study group, 49 patients (39\%) were current or ex-smokers, and 32 patients (25\%) were current smokers. None of them had previously received any pharmacological tobacco cessation therapy, according to their self-declared medical history. The patients smoked 20 cigarettes a day on average. Ex-smokers accounted for $14 \%(n=17)$ of the study population.

\section{Physical activity}

None of the patients in the study group were participating in any regular, long-lasting physical activity.

\section{Discussion}

The main finding of this study is that in the group of PAD claudicants admitted to an angiology outpatient unit, the atherosclerosis risk factors had been underestimated and when diagnosed, they were treated incorrectly. The current study revealed that $77 \%$ of PAD patients were diagnosed with dyslipidemia, $72 \%$ had hypertension and $31 \%$ had diabetes. Suboptimal treatment was received by $85.5 \%$ of patients with dyslipidemia, $26 \%$ of patients with hypertension and $95 \%$ of diabetics. In this study, dyslipidemia, 
hypertension and diabetes were diagnosed for the $1^{\text {st }}$ time in $22 \%, 7 \%$ and $4 \%$ of the subjects, respectively. A total of $17.5 \%$ of PAD patients with claudication were not receiving any antiplatelet therapy.

\section{Lipid-lowering therapy}

The ESC guidelines require an active search for atherogenic dyslipidemia in symptomatic PAD patients and, following diagnosis, aggressive lipid-lowering therapy. All patients with PAD should have their serum LDL cholesterol reduced to $<100 \mathrm{mg} / \mathrm{dL}$, or to $<70 \mathrm{mg} / \mathrm{dL}$, ideally; when the target level cannot be reached, the physician should consider lowering the LDL cholesterol by $50 \%$ or more of the level before treatment, according to the guidelines (class of recommendation: I, level of evidence: C). The most important medications which reduce the risk of mortality, cardiovascular events and stroke, and those which increase the absolute walking distance in patients with PAD with and without coronary heart disease (CHD), are statins, especially simvastatin. ${ }^{1,3,6-8}$

The data revealed that $77 \%$ of PAD patients were dyslipidemic before the study began, and that a further $22 \%$ of subjects were not diagnosed with dyslipidemia beforehand. Nonetheless, when dyslipidemia was diagnosed, only $14.4 \%$ of the affected subjects achieved the goals of ESC treatment for LDL levels. These results could be the consequence of not following the guidelines or they may suggest a lack of awareness on the part of physicians and patients, who did not test for dyslipidemia. The 2 main types of statins administered were atorvastatin in $76 \%$ of patients $(n=67)$ and simvastatin in $20 \%$ of patients $(n=17)$.

\section{Antihypertensive drugs}

All patients with PAD, according to the ESC guidelines, should have their blood pressure reduced to $\leq 140 / 90 \mathrm{~mm} \mathrm{Hg}$ (class of recommendation: I, level of evidence: A). ${ }^{1,4}$ Treatment with angiotensin-converting enzyme inhibitors has shown a beneficial effect by lowering blood pressure in high-risk groups. ${ }^{9,10}$ Importantly, beta-blockers are not contraindicated in patients with PAD (class of recommendation: IIa, level of evidence: B). Beta-blockers should be considered in the treatment of concomitant coronary artery disease and/or heart failure (class of recommendation: IIa, level of evidence: B). ${ }^{11}$

According to the results of this study, hypertension was detected in $72 \%$ of the study group, which was higher than the findings of the Framingham Offspring Study (69\%) and lower than the findings in the PARTNERS study (88\%). ${ }^{12,13}$ The detection of hypertension is imperative, but of even more importance to the current study is that $26 \%$ of patients with recognized hypertension were receiving suboptimal treatment. Seven percent of the entire study group had unrecognized hypertension. ${ }^{1,6}$ The detection of atherosclerosis risk factors and the achievement of treatment goals are better in the case of hypertension than in dyslipidemia in Poland. Nevertheless, almost $1 / 3$ of antihypertensive PAD subjects were receiving suboptimal treatment.

\section{Diabetes}

In patients with PAD and diabetes, the recommended $\mathrm{HbA}_{1 \mathrm{c}}$ level is $\leq 6.5 \%$ according to ESC criteria (class of recommendation: I, level of evidence: $C)^{1}$ and $\leq 7 \%$ according to American Diabetes Association (ADA) criteria (level of evidence: B). ${ }^{14}$ Diabetic PAD patients have poorer leg function, higher body mass index (BMI), increased neuropathy, and more cardiovascular comorbidities than PAD patients without diabetes. ${ }^{15-17}$ Additionally, inadequate treatment of diabetes increases the risk of mortality in PAD patients. ${ }^{12}$ For these reasons detection and treatment of diabetes in PAD patients should be imperative.

In the current study, $31 \%$ of patients had previously diagnosed diabetes. Prediabetes was found in $11 \%$ of cases and unrecognized diabetes was found in $4 \%$, using only the venous fasting glycaemia test. The majority of diabetics (95\%) were being undertreated, with an $\mathrm{HbA}_{1 \mathrm{c}}$ level higher than the recommended range. The study revealed that although the recognition of diabetes seems to be sufficient in PAD patients in Poland, the level of inadequate treatment is considerable and requires improvement.

\section{Antiplatelet and antithrombotic therapy}

According to ESC guidelines, the incidence of vascular death, non-fatal myocardial infarction and non-fatal stroke was significantly reduced at follow-up by the use of antiplatelet drugs (class of recommendation: I, level of evidence: C) ${ }^{1,18}$ A low dose of aspirin (75-100 mg daily) was at least as effective as higher daily doses. ${ }^{1}$ The CAPRIE trial demonstrated that clopidogrel is as efficacious as aspirin in preventing major cardiovascular events in patients with PAD. ${ }^{19}$ The insignificant benefits of dual antiplatelet therapy do not overcome the increased risk of bleeding in patients with PAD, so its recommendation is not justified. ${ }^{20,21}$ Antiplatelet therapy is recommended in all patients with symptomatic PAD. ${ }^{1}$

In the current study, $82.5 \%$ of the entire population were using antiplatelet therapy. Aspirin (an average daily dose of $150 \mathrm{mg}$ ), as a recommended therapy, was the most common antiplatelet therapy (59\%), followed by clopidogrel and ticlopidine in the same proportions (1.6\%). Anticoagulation therapy was being used in $4 \%$ of cases. Approximately $17.5 \%$ of the patients in the study sample $(n=22)$ were not currently receiving antiplatelet or anticoagulant therapy, but no contraindications to this therapy were identified in this group of patients. Moreover, $15 \%$ of the subjects were administered dual antiplatelet therapy, without any cardiological or angiosurgical indications for such treatment. 


\section{Other medicines taken for peripheral artery disease}

Phosphodiesterase inhibitor was one of the $1^{\text {st }}$ drugs used in patients with arteriosclerosis obliterans. It improves the rheological properties of blood and is also believed to increase the claudication distance by about $100 \mathrm{~m} .{ }^{22}$ Our study revealed that 35 subjects from the entire population (only 28\%) were taking pentoxifylline, with an average dose of $1200 \mathrm{mg}$ per day (600-1800 mg ). Sulodexide was taken by 13 patients (10.3\%), with an average dose of $500 \mathrm{mg}$ per day. Bencyclane was taken by 15 patients $(12 \%)$ at an average dose of $400 \mathrm{mg}$ per day.

\section{Lifestyle modifications}

Smoking is an important risk factor for PAD. In the general population, smoking increases the risk of PAD between 2-fold and 6-fold. Current smokers with PAD have an increased risk of limb amputation and are at an increased risk of postoperative complications and mortality. ${ }^{23-25}$ Smokers should be advised to quit smoking and be offered smoking cessation programs (class of recommendation: I, level of evidence: $B){ }^{1}$

A limitation of the study was the use of self-reported smoking history without validating it by means of biological markers. Out of the 126 patients who were admitted to the outpatient angiology unit with a low walking distance, 25\% were active smokers. This number seems very low in comparison to the PARTNERS study and the Rotterdam Study, in which $70 \%$ of the PAD patients were active smokers. ${ }^{25}$

Non-pharmacological methods of improving the length and quality of life in the form of a balanced diet, weight control and regular exercise were not being used by any of the patients.

\section{Conclusions}

There is a strong need to carefully diagnose dyslipidemia in PAD patients. The prescription of antiplatelet therapy to PAD patients should be more widespread. The rate of hypertension and diabetes in PAD patients appears to be high, but physicians should place greater emphasis on achieving optimal treatment goals.

\section{References}

1. European Stroke Organisation, Tendera M, Aboyans V, Bartelink ML, et al.; ESC Committee for Practice Guidelines. ESC Guidelines on the diagnosis and treatment of peripheral artery diseases. Eur Heart $J$. 2011;32(22):2851-2906.

2. Gardner A, Montgomery P, Flinn W, Katzel LI. The effect of exercise intensity on the response to exercise rehabilitation in patients with intermittent claudication. J Vasc Surg. 2005;42(4):702-709.

3. Goff DC, Bertoni AG, Kramer H, et al. Dyslipidemia prevalence, treatment, and control in the multi-ethnic study of atherosclerosis (MESA): Gender, ethnicity, and coronary artery calcium. Circulation. 2006;113(5):647-656.
4. James PA, Oparil S, Carter BL, et al. Evidence-based guideline for the management of high blood pressure in adults: Report from the panel members appointed to the Eighth Joint National Committee (JNC 8). JAMA. 2014;311(5):507-520.

5. World Health Organization. Definition and diagnosis of diabetes mellitus and intermediate hyperglycaemia: Report of a WHO/IDF consultation. Geneva, Switzerland: World Health Organization; 2006.

6. Graham I, Atar D, Borch-Johnsen K, et al.; European Society of Cardiology (ESC); European Association for Cardiovascular Prevention and Rehabilitation (EACPR); Council on Cardiovascular Nursing; European Association for Study of Diabetes (EASD); International Diabetes Federation Europe (IDF-Europe); European Stroke Initiative (EUSI); International Society of Behavioral Medicine (ISBM); European Society of Hypertension (ESH); European Society of General Practice/Family Medicine (ESGP/FM/WONCA); European Heart Network (EHN). European guidelines on cardiovascular disease prevention in clinical practice: Executive summary. Fourth Joint Task Force of the European Society of Cardiology and other societies on cardiovascular disease prevention in clinical practice (constituted by representatives of nine societies and by invited experts). Eur Heart J. 2007;28:2375-2414.

7. European Association for Cardiovascular Prevention \& Rehabilitation, Reiner Z, Catapano AL, De Backer G, et al.; ESC Committee for Practice Guidelines (CPG) 2008-2010 and 2010-2012 Committees. ESC/EAS guidelines for the management of dyslipidaemias: The Task Force for the management of dyslipidaemias of the European Society of Cardiology (ESC) and the European Atherosclerosis Society (EAS). Eur Heart J. 2011;32(14):1769-1818.

8. Collins R, Armitage J, Parish S, Sleigh P, Peto R; Heart Protection Study Collaborative Group. MRC/BHF Heart Protection Study in cholesterol-lowering with simvastatin in 5963 people with diabetes: A randomized placebo-controlled trial. Lancet. 2003;361(9374):2005-2016.

9. The Heart Outcomes Prevention Evaluation Study Investigators, YusufS, Sleight P, Pogue J, Bosch J, Davies R, Dagenais G. Effects of an angiotensin-converting-enzyme inhibitor, ramipril, on cardiovascular events in high risk patients. N Eng/ J Med. 2000;342(3):145-153.

10. ONTARGET Investigators, Yusuf S, Teo KK, Pogue J, et al. Telmisartan, ramipril or both in patients at high risk for vascular events. N Engl JMed. 2008;358(15):1547-1559.

11. Radack K, Deck C. Beta-adrenergic blocker therapy does not worsen intermittent claudication in subjects in peripheral arterial disease. A meta-analysis of randomized, controlled trials. Arch Intern Med. 1991;151(9):1769-1776.

12. Murabito JM, Evans JC, Nieto K, Larson MG, Levy D, Wilson PW. Prevalence and clinical correlates of peripheral arterial disease in the Framingham Offspring Study. Am Heart J. 2002;143(6):961-965.

13. Hirsh AT, Criqui MH, Treat-Jacobson D, et al. Peripheral arterial disease detection, awareness, and treatment in primary care. JAMA. 2001;286(11):1317-1324.

14. American Diabetes Association. Standards of Medical Care in Diabetes - 2014. Diabetes Care. 2014;37(Suppl 1):S14-80.

15. Resnic $H$, Shorr R, Kuller L. Prevalence and clinical implications of American Diabetes Association-defined diabetes and other categories of glucose dysregulation in older adults: The health, aging and body composition study. J Clin Epidemiol. 2001;54(9):869.

16. Hiatt WR. Preventing atherotrombotic events in peripheral arterial disease: The use of antiplatelet therapy. J Intern Med. 2002;251(1):93-206.

17. Dawson DL, Hiatt WR, Creager MA, Hirsch AT. Peripheral arterial disease: Medical care and prevention of complications. Prev Cardiol. 2002;5:119-130.

18. Antithrombotic Trialists' (ATT) Collaboration, Baigent C, Blackwell L, Collins $\mathrm{R}$, et al. Aspirin in the primary and secondary prevention of vascular disease: Collaborative meta-analysis of individual participant data from randomized trials. Lancet. 2009;373(9678):1849-1860.

19. CAPRIE Steering Committee. A randomized, blinded, trial of clopidogrel versus aspirin in patients at risk of ischemic events (CAPRIE). Lancet. 1996;348(9038):1329-1339.

20. Bhatt DL, Fox KA, Hacke W, et al. CHARISMA Investigators. Clopidogrel and aspirin versus aspirin alone for the prevention of atherotrombotic events. N Engl J Med. 2006;354(16):1706-1717.

21. Cacoub PP, Bhatt DL, Steg PG, Topol EJ, Creager MA; CHARISMA Investigators. Patients with peripheral arterial disease in the CHARISMA trial. Eur Heart J. 2009;30(2):192-201. 
22. Momsen $A H$, Jensen $M B$, Norager CB, Madsen MR, Vestergaard-Andersen $T$, Lindholt JS. Drug therapy for improving walking distance in intermittent claudication: A systematic review and meta-analysis of robust randomized controlled studies. Eur JVasc Endovasc Surg. 2009;38(4):463-474.

23. Fowkes FG, Housley E, Riemersma RA, et al. Smoking, lipids, glucose intolerance, and blood pressure as risk factors of peripheral atherosclerosis compared with ischaemic heart disease in the Edinburgh Artery Study. Am J Epidemiol. 1992;135(4):331-340.
24. Criqui MH. Peripheral artery disease - epidemiological aspects. Vasc Med. 2001;6:3-7.

25. Powell JT, Edwards RJ, Worrell PC, Franks PJ, Greenhalgh RM, Poulter NR. Risk factors associated with the development of peripheral arterial disease in smokers: A case-control study. Atherosclerosis. 1997;129(1):41-1248. 